\title{
Avaliação e percepção: a expressividade de cláusulas
}

\author{
justapostas
}

\author{
Evaluación y percepción: la expresividad de cláusulas \\ yuxtapuestas
}

\section{Evaluation, perception: the expressiveness of juxtaposed}

\author{
clauses
}

Adriana Cristina Lopes Gonçalves Mallmann, ${ }^{*}$ Violeta Virginia Rodrigues**

RESUMO: O presente estudo busca mostrar como a justaposição, processo sintático caracterizado pela interdependência semântica e independência sintática entre cláusulas, é avaliado e percebido em mídias impressas por alunos do Ensino Médio e do Ensino Superior e por professores de Língua Portuguesa, História e Geografia, que lecionam no Ensino Médio. Para tal intento, emprega-se o aporte teórico da sociolinguística variacionista e alguns conceitos do funcionalismo, tomando como base, principalmente, os estudos de Eckert (2008), Freitag et al. (2016), Bakhtin (2013), Gonçalves (2017), Rodrigues e Gonçalves (2015). Os resultados obtidos a partir de um teste linguístico de percepção demonstram uma avaliação coerente e pertinente sobre os recursos linguísticos e semióticos ratificada pela rede de sentidos estabelecida (+/formal, criativo, expressivo, interacional e autêntico). Além disso, os resultados reforçam a tese de Bakhtin (2013) sobre a avaliação dos alunos acerca da maior expressividade de orações subordinadas sem conectivo, a qual foi adaptada ao uso das cláusulas justapostas.

PALAVRAS-CHAVE: Justaposição. Avaliação. Percepção. Ensino.

RESUMEM: El presente estudio busca mostrar cómo la yuxtaposición, proceso sintáctico caracterizado por la interdependencia semántica y la independencia sintáctica entre cláusulas, es evaluado y percibido en los medios impresos por

\footnotetext{
* Doutoranda em Língua Portuguesa pela Faculdade de Letras da Universidade Federal do Rio de Janeiro, UFRJ, Rio de Janeiro, RJ, com bolsa de doutorado pelo programa Capes/UFRJ. Email: adrianaclgoncalves@hotmail.com

** Professor associado IV da UFRJ, integrando o quadro de docentes permanentes do Departamento de Letras Vernáculas - Setor de Língua Portuguesa, atuando nos cursos de Graduação e no Programa de Pós-Graduação em Letras Vernáculas da Universidade Federal do Rio de Janeiro, UFRJ, Rio de Janeiro, RJ. E-mail violeta.rodrigues@letras.ufrj.br
} 
estudiantes de secundaria y educación superior y por profesores de Lengua Portuguesa, Historia y Geografía, que enseñan en la secundaria. Para este propósito, se utiliza la contribución teórica de la sociolingüística variacionista y algunos conceptos del funcionalismo y se basa principalmente en los estudios de Eckert (2008), Freitag et al. (2016), Bakhtin (2013), Gonçalves (2017), Rodrigues y Gonçalves (2015). Los resultados obtenidos a partir de un test de percepción lingüística demuestran una evaluación coherente y suficiente de los recursos lingüísticos y semióticos ratificados por la red de sentidos establecida (+/- formal, creativo, expresivo, interactivo y auténtico). Además, los resultados refuerzan la tesis de Bakhtin (2013) sobre la evaluación de los estudiantes sobre la mayor expresividad de las cláusulas subordinadas sin un conectivo que se ha adaptado al uso de cláusulas yuxtapuestas.

PALABRAS CLAVE: Yuxtaposición. Evaluación. Percepción. Enseñanza.

ABSTRACT: The present study presentes how the juxtaposition, a syntactic process characterized by semantic interdependence and syntactic independence between clauses, is evaluated and perceived in print media by high school students and teachers of Portuguese Language, History and Geography who teach in High School. For that purpose, it was used the theoretical contribution of sociolinguistic variability and some concepts of functionalism. It was alsotaken as a basis, mainly, the studies of Eckert (2008), Freitag et al. (2016), Bakhtin (2013), Gonçalves (2017), Rodrigues and Gonçalves (2015). The results obtained from a linguistic test of perception demonstrate a coherent and sufficient evaluation of the linguistic and semiotic resources ratified by the established network of meanings ( $+/-$ formal, creative, expressive, interactive and authentic). In addition, the results confirm Bakhtin's (2013) thesis about students' evaluation of the greater expressiveness of juxtaposed clauses.

KEYWORDS: Juxtaposition. Evaluation. Perception. Teaching.

\section{Introdução}

O presente artigo tem como objetivo mostrar como a justaposição, entendida aqui como um processo sintático de articulação de cláusulas, é avaliada e percebida por alunos de Ensino Médio, da Graduação e por professores de Língua Portuguesa e de outras áreas em slogans de mídias impressas. Tal estudo se justifica, pois há poucos trabalhos acerca deste processo na literatura linguística; além disso, faz-se necessário verificar como os indivíduos mais ou menos escolarizados avaliam o uso das cláusulas justapostas (+/- formal, criativo, expressivo, só para citar algumas possíveis avaliações). 
A motivação para a realização desse estudo advém, principalmente, das dissertações de mestrado de Dias (2009) e Gonçalves (2017), que investigaram o processo da justaposição, e do estudo de Bakhtin $\left(2013^{1}\right)$, no qual se problematiza a necessidade de se repensarem as práticas escolares, a fim de dar conta de estruturas estigmatizadas pela escola, como acontece com as cláusulas justapostas. Nesse caso, cumpre ressaltar que, embora as cláusulas justapostas sejam empregadas em interações comunicativas diárias, essas são frequentemente esquecidas pela escola e avaliadas em concursos de forma negativa, pois são frequentemente associadas à falta de emprego de conectivos que, por sua vez, é relacionada aos mecanismos de coesão textual nas aulas de redação.

Para atingir tal intento, esse trabalho utiliza como fundamentação teórica a sociolinguística variacionista, relacionando-a com a perspectiva funcionalista. Do funcionalismo adotamos a premissa de que o discurso molda a língua e é moldado por ela, tendo em vista que investigamos os usos efetivos de língua em contextos reais de interação, nesse caso, o uso de períodos compostos por justaposição em mídias impressas. A sociolinguística variacionista, além de permitir a investigação de algumas variáveis dependentes como nível de escolaridade e sexo, nos possibilitou a análise de como os indivíduos avaliam e percebem certas formas gramaticais, no caso, as cláusulas justapostas.

Para tanto, foram aplicados testes de percepção constituídos de duas partes. A primeira formada pela técnica do match-guise (FASOLD, 1984) e tendo como objetivo avaliar a percepção dos informantes sobre a relação estabelecida entre o slogan e os recursos linguísticos e semióticos que compõem as mídias impressas como, por exemplo, +/- formal, +/- criativo, +/expressivo, só para citar algumas possíveis avaliações. A segunda parte composta de perguntas abertas sobre o gênero textual, recursos linguísticos e semióticos, e emprego de conectores.

Sendo assim, esse artigo pretende descrever como a justaposição é avaliada por falantes com diferentes graus de escolaridade e em estágios

\footnotetext{
${ }^{1}$ Essa data se refere à edição do livro intitulado Questões de estilística no ensino da língua.
} 
distintos de cognição. Além disso, busca também comparar essa avaliação, em especial sobre o critério expressividade, conforme o trabalho proposto por Bakhtin (2013).

Além desta introdução, o conteúdo desse trabalho distribui-se pelas seguintes seções: apresentação do tema, pressupostos teóricos, metodologia e corpus, resultados, proposta de aplicação didática, considerações finais, referências e anexo.

\section{Apresentação do Tema}

A justaposição, fenômeno linguístico abordado nesse estudo, não é reconhecida como um processo sintático de articulação de cláusulas nas gramáticas tradicionais. Essas, ao contrário, reconhecem como processos sintáticos apenas a coordenação e a subordinação. A coordenação é descrita pela maioria dos gramáticos como processo sintático constituído por orações independentes do ponto de vista sintático e semântico, ou seja, a oração coordenada não é um termo da oração a que se liga e, por isso, possui autonomia sintática e, às vezes, de sentido. Já a subordinação é definida como um processo sintático em que as orações são dependentes do ponto de vista sintático e semântico, isto é, a oração subordinada exerce função sintática na oração principal ou em um termo dessa e depende desta oração para estabelecer comunicação. Desse modo, nota-se que as gramáticas tradicionais adotam, principalmente, a noção de (in)dependência sintática e semântica para definir os processos sintáticos da coordenação e da subordinação. No entanto, essa diferenciação não é suficiente, visto que essa noção de dependência e independência não costuma considerar as possíveis, e muitas, funções das orações aplicadas ao discurso, como as cláusulas justapostas, conforme ilustra o exemplo a seguir: 
Figura 1 - Propaganda da sessão Populares do jornal $O$ Povo

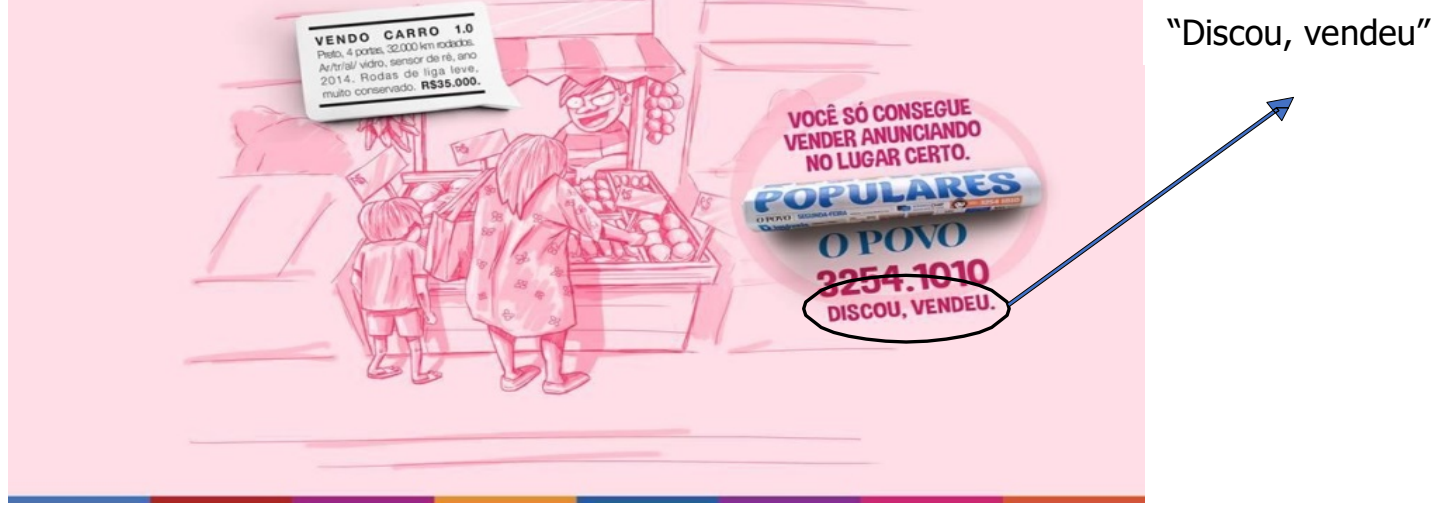

Fonte: Autoras.

No slogan "Discou, vendeu" (propaganda do jornal $O$ povo) as orações "discou" e "vendeu" são classificadas pela Gramática Tradicional (GT) como coordenadas assindéticas, pois são estruturas independentes do ponto de vista sintático, isto é, não funcionam como constituinte sintático uma da outra e, além disso, não possuem um conector que as relacione. Entretanto, de acordo com Rodrigues e Gonçalves (2015) e Gonçalves (2017), apesar do slogan não possuir conector ligando as duas orações que o formam, leituras circunstanciais podem emergir do contexto e do cotexto da propaganda, como atestam as leituras a seguir:

$$
\begin{gathered}
\text { (Se) "disca, vende". } \\
\text { (Porque) "disca, vende". }
\end{gathered}
$$

A relação semântica inferida pela articulação de uma oração com a outra caracteriza o que as autoras denominam de interdependência semântica, levando-as a considerarem períodos como esses como compostos por justaposição. A partir desse exemplo, percebe-se que a definição da tradição acerca dos processos sintáticos de articulação de cláusulas não considera o conteúdo circunstancial implícito neste tipo estrutura. Esse conteúdo circunstancial, além de ser uma característica intrínseca ao gênero propaganda, 
confere ao texto eficácia comunicativa.

Sendo assim, à luz dos trabalhos de autores pré NGB, como Oiticica (1942) e Ney (1955), do estudo descritivo de Raposo et al. (2013) e, principalmente, das pesquisas funcionalistas de Decat (1999), Lima-Hernandes (2008), Dias (2009), Rodrigues (2010), Rodrigues e Gonçalves (2015) e Gonçalves (2017), defende-se, nesse artigo, que a justaposição, no gênero textual propaganda, contexto em que há grande incidência dessa estrutura, é um processo sintático de articulação de cláusulas distinto da coordenação.

Dessa forma, entende-se que a coordenação como processo sintático é caracterizada pela independência sintática e semântica entre as orações, podendo a oração coordenada ser introduzida ou não por conector; ademais, não há pausa, fator prosódico, entre as cláusulas, o que demonstra que as informações que constituem o período coordenado são vistas como independentes. Já a justaposição é caracterizada pela pausa intercalada entre as cláusulas, pela autonomia sintática, pela ausência de conector introduzindo as cláusulas e pela interdependência semântica, com maior frequência da proposição relacional do grupo de causalidade, como atestam os resultados obtidos por Gonçalves (2017).

\section{Pressupostos Teóricos}

Nesse artigo, para uma descrição mais adequada do processo sintático da justaposição, correlacionamos a sociolinguística variacionista e o funcionalismo. Essas duas correntes podem ser imbricadas visto que, segundo Eckert (2008, p. 453), "a variação como todo, inclusive a variação linguística, deve ser integrada em uma compreensão mais ampla de língua como prática social" ${ }^{\prime 2}$, por isso, é preciso investigar como os falantes avaliam e percebem as cláusulas justapostas utilizadas frequentemente em mídias impressas em

\footnotetext{
2 "the variation (and the entire linguistic) enterprise must be integrated into a more comprehensive understanding of language as social practice" (ECKERT, 2008, p. 453, tradução livre).
} 
comparação com as demais cláusulas hipotáticas e encaixadas ${ }^{3}$ também empregadas, com menos frequência, nesse gênero textual. Portanto, no uso, conforme defende o funcionalismo.

Além disso, a autora ressalta que "os significados atribuídos as variantes não são precisos e fixos, ao contrário esses constituem um campo de sentidos em potencial - um campo "indexal" ou uma constelação ideológica de sentidos relacionados, em que qualquer um dos sentidos pode ser ativado em uma determinada situação comunicativa de uso da variação" (ECKERT, 2008, p. $454)^{4}$.

Desse modo, Eckert (2008) apresenta a importância de relacionar variação, estilo e significado socialmente construído com o intuito de pensar os usos linguísticos; em outras palavras, para a linguista, o uso linguístico envolve uma análise e interpretação contínua de categorias, grupos, tipos e construção de personas que, consequentemente, influencia na seleção vocabular e sintática que um indivíduo emprega em determinado contexto.

Sobre a prática estilística, concebida nesse artigo como processo de interpretação e combinação individual de recursos linguísticos para construir estruturas mais complexas e significativas, Bakhtin (2013) aponta a inefícácia da escola em apresentar usos linguísticos que, apesar de serem frequentemente empregados em contextos diversos, não são prescritos nas gramáticas normativas. Segundo o pesquisador,

"[...] as formas gramaticais não podem ser estudadas sem que se leve em conta seu significado estilístico. Quando isolada dos aspectos semânticos e estilísticos da língua, a gramática inevitavelmente degenera em escolasticismo". (BAKHTIN, 2013, p. 7).

Bakhtin (2013) analisa especificamente "períodos compostos por

3 "the variation (and the entire linguistic) enterprise must be integrated into a more comprehensive understanding of language as social practice" (ECKERT, 2008, p. 453, tradução livre).

4 "[...] the meanings of variable are not precise or fixed but rather constitute a field of potencial meanings - an indexical field, or constellation of ideologically related meanings, any one of which can be activated in the situated use of the variable". (ECKERT, 2008, p. 454, tradução livre). 
subordinação sem conjunção", cujos pressupostos foram adaptados nesse trabalho para a abordagem dos períodos que denominamos compostos por justaposição, constituído pelas cláusulas justapostas. Sobre os "períodos compostos por subordinação sem conjunção", o autor aponta a necessidade de articular gramática e estilística no ensino dessas estruturas, levando em consideração os diversos efeitos de sentido que uma cláusula pode gerar, dependendo da conjunção utilizada. No caso das cláusulas justapostas, os efeitos de sentido gerados pela omissão desses conectores. O pesquisador enfatiza também que o uso das conjunções subordinativas pode acarretar a perda da expressividade, como se verifica na paráfrase do slogan no exemplo a seguir. O slogan "Não fique preso, viva o Inglês" composto por duas cláusulas justapostas (primeira cláusula "Não fique preso"; segunda, "viva o Inglês) pode acarretar diversas leituras como de causa, consequência, condição e proporcionalidade, só para citar algumas. Entretanto, uma reescritura do slogan, como por exemplo, "[Se] fica preso, não vive o Inglês" acarreta uma delimitação do conteúdo semântico, impossibilitando o aluno de interpretar e interagir com a multiplicidade de sentidos oriundos dos recursos linguísticos e semióticos empregados na mídia impressa como se pode notar com o uso das cláusulas no contexto: 
Figura 2 - Propaganda "Solte o Inglês" do curso de idiomas Cultura Inglesa

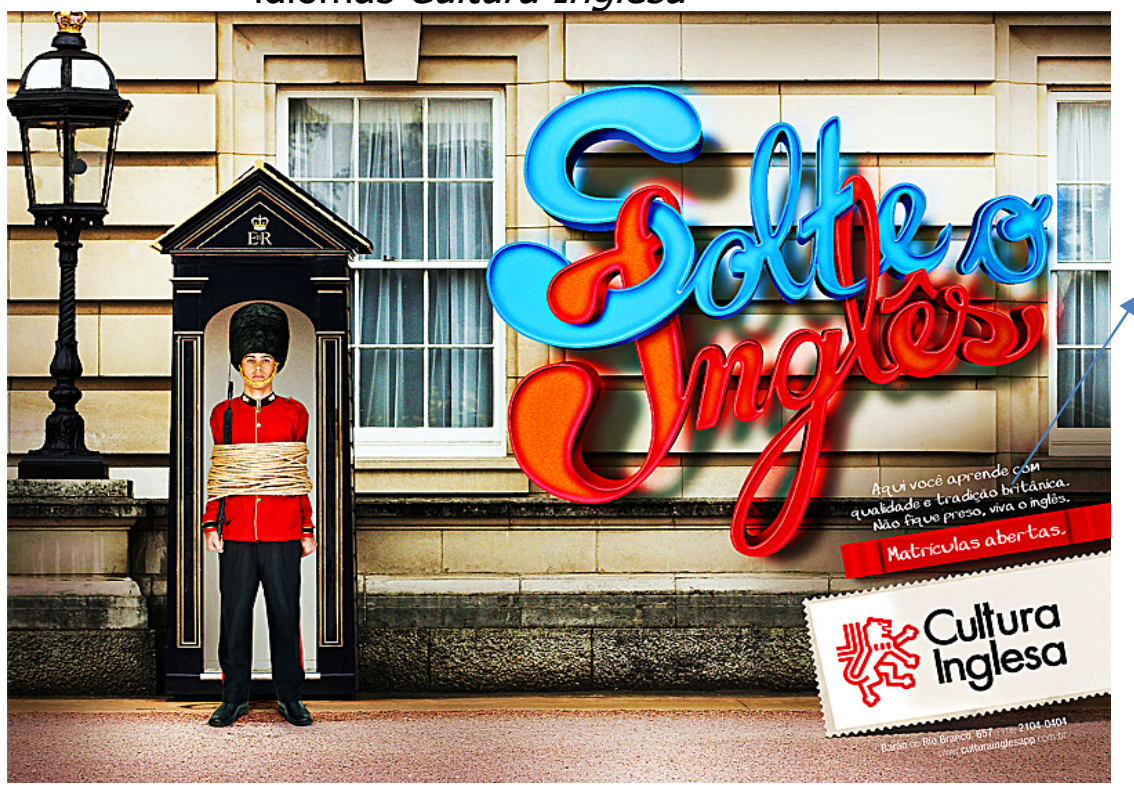

"Não fique preso, viva o inglês"

Fonte: Gonçalves (2017, p. 89).

A figura 2, uma propaganda do curso de Inglês Cultura Inglesa, tem como propósito comunicativo mais que a comercialização da aprendizagem do idioma, a aprendizagem do Inglês Britânico como cultura. Assim, para atingir esse propósito, são empregados diversos recursos semióticos associados a dois campos semânticos, mais especificamente, o da cultura Britânica, expresso pela oração "viva o inglês" e o do aprisionamento, expresso pela outra oração 5 do slogan "não fique preso".

Nota-se, portanto, que a imagem de fundo, o Palácio de Buckingham, residência oficial e principal local de trabalho do Monarca do Reino Unido em Londres, bem como a cabine da guarda real e soldado de infantaria localizados no canto esquerdo da imagem, fazem referência a cultura tradicional do Reino Unido. Já as cordas em torno do soldado fazem referência ao campo semântico de aprisionamento. Sendo assim, por meio da leitura dos aspectos semióticos, o slogan ganha mais expressividade, possibilitando, assim, a inferência da relação semântica de causa e consequência, [Porque] não fica preso, vive o Inglês, estratégia que atende ao que parece ser o propósito comunicativo principal da

\footnotetext{
${ }^{5}$ Entende-se por cláusula a unidade linguística que estabelece comunicação e que pode conter verbo ou não. Normalmente, tal noção é usada como sinônima de oração.
} 
propaganda: só no curso Cultura Inglesa é possível aprender a Língua Inglesa concomitante à cultura Britânica.

Além disso, Bakhtin (2013, p. 58) atesta que as estruturas sem conjunções são usadas nos gêneros literários para ilustrar um uso mais coloquial, por vezes, relacionado à fala, resultando em um enfraquecimento do aspecto monológico da língua e fortalecendo seu aspecto dialógico. Essa tendência, consequentemente, favorece uma formação mais próxima da atual de construções sintáticas da língua.

Portanto, com base no que Bakhtin (2013) havia feito e adaptando isso aos nossos propósitos, foi realizado um teste linguístico de percepção com o intuito de evidenciar a percepção estilística de falantes em diferentes níveis de escolarização. Tal teste será melhor descrito na seção metodologia e apresentado na íntegra na seção anexo.

\section{Metodologia e Corpus}

O corpus desse estudo é constituído por 12 (doze) entrevistas. Essas entrevistas foram realizadas em dois momentos. O primeiro momento consistiu na realização de um questionário em que foram utilizadas algumas mídias impressas nas quais se usaram períodos compostos por cláusulas justapostas e por cláusulas subordinadas; nesse caso, as cláusulas subordinadas foram utilizadas como uma estratégia para se comparar coordenadas/justapostas e como distrator simultaneamente. Vale explicitar que as mídias impressas utilizadas foram recolhidas de portfólios de 185 (cento e oitenta e cinco) agências publicitárias cadastradas no site da ABAP (Agência Brasileira de Agências Publicitárias). Sendo assim, nesta etapa, foi solicitado que 0 informante selecionasse em que nível o slogan da propaganda se encontrava em uma escala de ranqueamento, de um a cinco, em relação ao texto, isto é, se os recursos linguísticos e semióticos utilizados na propaganda em relação ao slogan são mais ou menos criativos, formais, expressivos, interacionais e autênticos (cf. anexo). $O$ segundo momento consistiu em uma entrevista. 0 
entrevistador, após acompanhar a realização da primeira etapa do teste, fez algumas perguntas ao entrevistado em relação ao gênero textual, a intenção comunicativa do gênero, os recursos semióticos e linguísticos empregados bem como a eficácia desses (cf. anexo).

Esse teste linguístico de percepção por meio da leitura foi realizado com o objetivo de comparar os resultados obtidos na pesquisa proposta por Bakhtin (2013), conforme discutido anteriormente na seção intitulada pressupostos teóricos. Este pesquisador realizou, ainda nos anos de 1940 na Rússia, entrevistas e interações com alunos de $1^{\text {a }}$ à $7^{a}$ série (equivalente no Brasil ao Ensino Fundamental) e de $8^{\mathrm{a}}$ à $10^{\mathrm{a}}$ série (que corresponde no Brasil ao Ensino Médio) acerca dos empregos de períodos compostos por subordinação sem conjunção na língua russa. Bakhtin (2013) aponta que, naquela época, era mais frequente o uso dessas estruturas por alunos da $1^{\text {a }}$ à $7^{a}$ série, já que a escola não recomendava o uso de períodos subordinados sem conector. Outra reflexão interessante que o estudioso aponta é que, quando os alunos das séries finais foram questionados sobre a expressividade das estruturas em questão, eles avaliaram que o uso de conector torna a estrutura menos expressiva. Desse modo, o autor ressalta que recomendar aos alunos para não usarem períodos sem conector ou a reescritura com conectores de períodos nos quais eles não foram empregados é perder expressividade, recomendação essa frequentemente realizada por manuais de redação que visam a concursos para ingresso em universidades públicas atualmente. $O$ que encontramos em Bakhtin (2013) serviu de motivação para testarmos a leitura das justapostas pelos alunos atualmente.

Sendo assim, o teste linguístico realizado para esse trabalho foi aplicado com três grupos com níveis distintos de escolaridade - alunos de Ensino Médio ( $1^{\circ}$ ano e $3^{\circ}$ ano), alunos da graduação ( $1^{\circ}$ período e 70 período) e professores graduados em Língua Portuguesa e humanas, Geografia e História, mais especificamente. $O$ teste foi aplicado em dois lugares, no Colégio Curso Carpe Diem, colégio particular localizado na Ilha do Governador, subúrbio do Rio de Janeiro, que tem como objetivo uma formação ampla e crítica dos alunos e, 
para isso, possibilita atividades interdisciplinares e complementares, e na Universidade Federal do Rio de Janeiro (UFRJ), mais especificamente na Faculdade de Letras, em turmas oriundas do curso de licenciatura em Letras do $1^{0}$ período e do 70 período.

Ademais, os níveis de escolarização, anos e períodos foram pensados com o objetivo de verificar como alunos em fase inicial e final do processo educacional avaliam o fenômeno. Quanto aos discentes, há dois grupos: os alunos do Ensino Médio e da Graduação. O primeiro grupo foi constituído por alunos do $1^{0}$ ano do Ensino Médio, fase transitória que prioriza criatividade, e os alunos do $3^{\circ}$ ano do Ensino Médio, fase em que há maior preocupação com o vestibular, principalmente com redação. Em relação ao critério coesão, é frequentemente recomendado pelos manuais de redação e bancas de vestibular um maior emprego de conectores, penalizando, portanto, períodos justapostos ou períodos em que não são utilizados conectores pelos escreventes. 0 segundo grupo é constituído por alunos do $1^{0}$ período da graduação, fase em que ainda há o vício da homogeneização textual proposta pelo vestibular, e alunos do 70 período, fase em que já há a construção do pensamento crítico em relação aos recursos utilizados nos diferentes gêneros textuais. Quanto aos docentes, foram selecionados professores de Língua Portuguesa, que possuem uma perspectiva mais crítica do ensino de Língua Portuguesa e possuem também um conhecimento mais aprofundado sobre língua, e professores da área de humanas, que possuem uma concepção de língua mais geral e voltada para o uso.

A nossa hipótese era a de que os alunos do primeiro ano e os professores de Geografia avaliariam mais positivamente e com maior naturalidade as cláusulas justapostas do que os alunos do terceiro ano, já que esses costumam estar mais atentos ao que prescrevem os manuais de redação, isto é, o emprego de conectores em períodos compostos. Quanto aos professores de Língua Portuguesa e os alunos da graduação, nos interessava identificar a avaliação e a justificativa dos usos das cláusulas justapostas elaboradas por eles, a fim de verificar como observavam o emprego das 
estruturas justapostas e suas finalidades estilísticas.

Assim, os testes pautaram-se, principalmente, nos trabalhos de Freitag et al. (2016) e Eckert (2008), que descrevem fenômenos em variação e as muitas redes de sentido que um indivíduo pode associar ao avaliar um fenômeno. Os resultados dos testes antes descritos podem ser vistos na seção a seguir.

\section{Resultados}

Os dados obtidos nas 12 (doze) entrevistas realizadas, foram analisados levando em conta 4 (quatro) aspectos: a rede de sentido associada à justaposição, isto é, a percepção dos falantes acerca do fenômeno linguístico; a avalição do fenômeno associada ao sexo, variante homem e mulher; a variante escolaridade e a variante nomeada "intra-escolaridade" - como indivíduos no mesmo grau de escolaridade, mas em estágio inicial e final observam o processo sintático. Vale ressaltar que, com o intuito de quantificar os dados recolhidos, consideramos, a priori, diferenças numéricas iguais ou acima de 0,5.

Quanto ao primeiro aspecto, a rede de sentidos associada às cláusulas justapostas, obtivemos o seguinte resultado: as cláusulas justapostas foram avaliadas como mais interacionais, mais ou menos criativas e formais e menos expressivas e autênticas, conforme ilustra a figura 3 a seguir. 
Figura 3 - Rede de sentidos das cláusulas justapostas

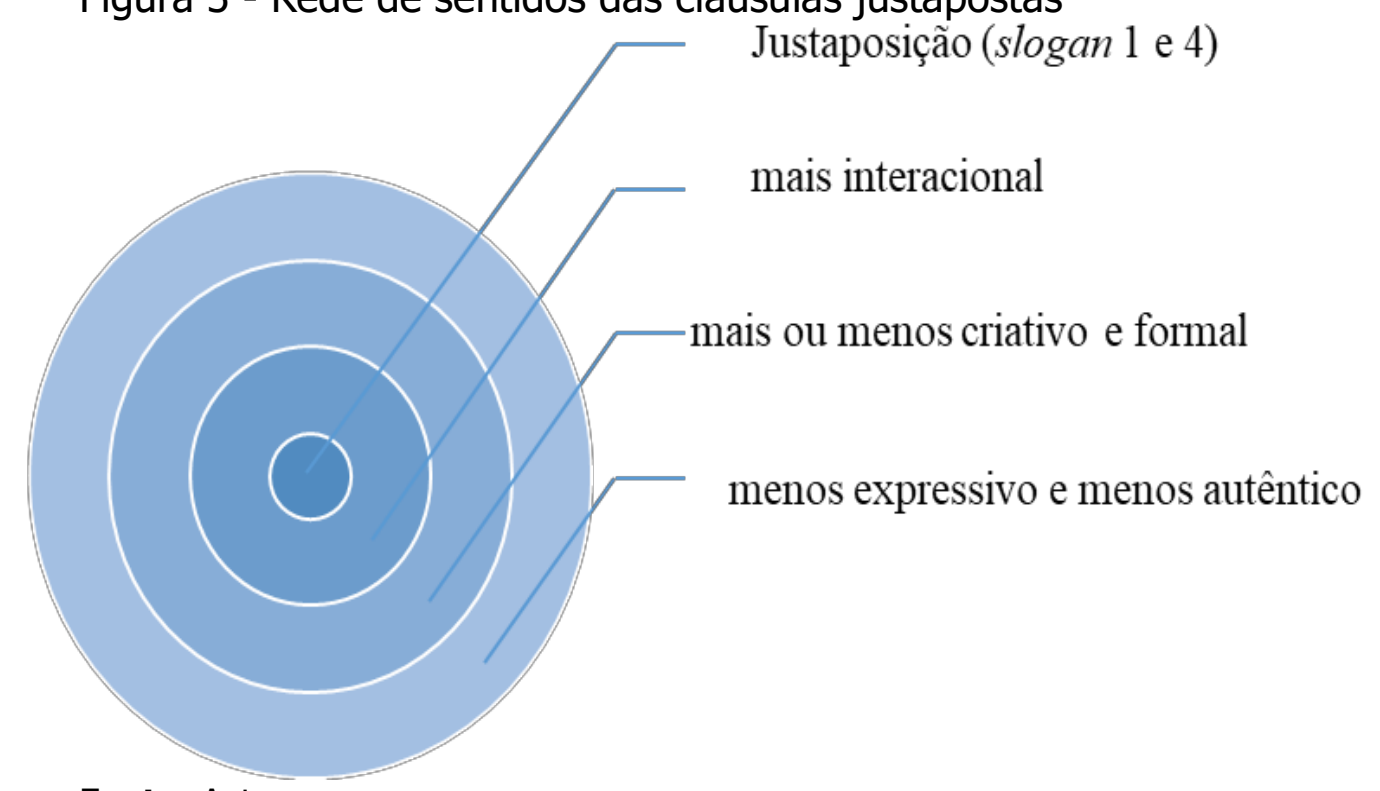

Fonte: Autoras.

Verificamos que, acerca da rede de sentidos, os informantes consideram como traço central do gênero propaganda e do recurso linguístico empregado, a justaposição, a interatividade, como fica explícito nos seguintes excertos:

O gênero propaganda torna-se importante, sobretudo, na observação sobre aspectos sociais já que atrelado a ele constrói-se uma ideologia articulada a um produto. Assim, vê-se como o leitor se posiciona sobre determinada situação cultural (PR_POR_H).

[O recurso linguístico] Ele auxilia para aumentar não somente a conexão com o leitor, mas ajuda o sentido da propaganda a se assegurar criando um canal comunicativo (AL_30 A_H).

Quanto à variável sexo, os homens avaliaram o fenômeno como [+ criativo, - formal, - autêntico]; já as mulheres avaliaram como [- criativo, + formal, + autêntico]. Essa percepção feminina, quanto ao gênero propaganda e os recursos nela usados, fica evidente no trecho a seguir:

[Os recursos visuais empregados nas propagandas que você viu são adequados e interessantes ao público alvo?]

Na maioria dos casos sim. No primeiro, ainda que tentasse fazer uma relação entre os classificados e a feira, eu não achei tão interessante ou criativo (AL_7OP_M).

Quanto ao nível de escolaridade, comparando os três grupos - superior 
completo, superior incompleto e Ensino Médio - com as redes de sentido, obtivemos os seguintes resultados:

Quadro 1 - Rede de sentidos associada à escolaridade

Rede de sentido Mais Médio Menos

\begin{tabular}{llll}
\hline Criativo & Superior incompleto & Ensino Médio & Superior completo \\
\hline Formal & Ensino Médio & Superior completo & Superior incompleto \\
\hline Expressivo & Superior incompleto & Ensino Médio & Superior completo \\
\hline Interacional & Superior incompleto & Ensino Médio & Superior completo \\
Autêntico & Superior incompleto & Ensino Médio & Superior completo
\end{tabular}

Fonte: Autoras.

As avaliações atribuídas às propagandas justapostas [+/- criativo, expressivo, interacional e autêntico] foram muito semelhantes, com exceção da avaliação do grau de formalidade.

Os resultados quantitativos sobre a avaliação dos aspectos [+/- criativo, expressivo, interacional e autêntico] em concomitância com as entrevistas demonstraram que os alunos da licenciatura em Letras da UFRJ têm um posicionamento muito crítico e instrumentalizado sobre os gêneros textuais, como evidencia a resposta a seguir:

Acredito que [a propaganda] seja um gênero bem expressivo, que é agradável aos olhos do leitor, visto que neste mesclam-se a parte visual e verbal para a construção do sentido. Acho que é um gênero interessante para os leitores em geral sim e que, para além disso, possui características interessantes para se trabalhar em âmbito escolar por se tratar de um recorte em que podemos ver/analisar a língua em funcionamento. (AL_7OP_M).

Ademais, sobre o aspecto grau de formalidade, a avaliação do Ensino Médio como mais formal do que o superior completo seguido do Superior incompleto, demonstra que, quanto maior o nível de escolaridade, maior é a intimidade e pensamento crítico acerca do gênero textual, dos recursos 
envolvidos e da função pragmática desses. As respostas explicitadas a seguir, de um informante com ensino superior completo e de outro com ensino superior incompleto, respectivamente, ilustram isso:

\begin{abstract}
[O que você espera desse tipo de texto (em relação à intenção comunicativa)?]

Que seja um texto claro e não tão formal e que chame o leitor à reflexão (PR_GE_M).

[Como esse tipo de recurso linguístico (frase, orações ou períodos) auxilia ou não na construção de sentido nesse gênero?]

Acho que auxilia como suporte para a transmissão da mensagem, ou como efeito humorístico - dando uma conotação mais (sutil e coloquial) cômica, mas que não comprometa a mensagem, apenas capte a atenção do leitor (AL_70P_M).
\end{abstract}

Quanto à posição proposta dentro dos níveis de escolarização, identificamos que os professores de Língua Portuguesa avaliaram um nível a mais em todos os quesitos quando comparados aos professores de outras áreas; os alunos do $1^{0}$ período avaliaram as propagandas compostas por cláusulas justapostas como mais interacionais do que os alunos do 70 período e os níveis preenchidos pelos alunos do $1^{0}$ ano e do $3^{\circ}$ ano do Ensino Médio foram muito semelhantes. Algumas respostas do questionário aberto chamaram atenção pela consciência quanto à necessidade de correlacionar recursos linguísticos e semióticos com o intuito de promover a interatividade, como se nota nas seguintes colocações:

Os recursos visuais são interessantes e adequados pois empregam um conjunto de elementos que chama a atenção do leitor e condizem com o propósito do texto (AL_30 A_H).

Na propaganda (i), 'Discou, vendeu', o leitor reconhece os benefícios de uma compra barata porque o elemento não verbal adotado é uma feira, o que é amplamente reconhecido por uma minoria de leitores. 0 slogan é curto e objetivo, o que ajuda na fixação da ideia e facilita a vendagem (PR_POR_H).

Sendo assim, percebemos que, ao contrário do que foi pressuposto na hipótese inicial, os alunos do $1^{0}$ e $3^{\circ}$ ano do Ensino Médio avaliaram de forma muito semelhante os slogans. Já os alunos da graduação em Letras e os 
professores de Língua Portuguesa, como se pressupunha na hipótese inicial, apresentaram avaliações adequadas acerca dos recursos linguísticos empregados e da finalidade comunicativa do gênero propaganda.

Vale ressaltar que, no quesito expressividade, os alunos do Ensino Médio avaliaram as propagandas constituídas por cláusulas justapostas como mais expressivas, seguidos pelos alunos da graduação e depois pelos professores. A resposta transcrita a seguir deixa clara essa avaliação:

"Os recursos linguísticos dão o sentido à imagem, que sozinha fica pouco expressiva, ou seja, ela depende dos recursos linguísticos para formar um sentido e, consequentemente, uma propaganda expressiva"(AL_1 $\left.{ }^{\circ} \mathrm{A} \_\mathrm{M}\right)$.

Os resultados antes apresentados reiteram o que Bakhtin (2013) já observara lá em 1940 sobre a língua russa, ou seja, que os alunos avaliam que o uso de conector torna a estrutura menos expressiva. Sendo assim, tudo indica que o ensino dos gêneros textuais nas últimas décadas, influenciado principalmente pela inclusão desse conteúdo nos documentos oficiais que regem o ensino brasileiro, a saber, (PCN) Parâmetros Curriculares Nacionais (BRASIL, 1998, 2000), auxiliou também em uma leitura mais refinada da aplicação dos recursos gramaticais, no nosso caso, uso ou não do conector, ao texto, proporcionando uma construção de sentido e uma adequação à situação comunicativa.

\section{Proposta de Aplicação Didática}

Uma possível e viável aplicação didática como desdobramento dos resultados dessa pesquisa poderiam ser as sugestões de atividades que se seguem.

Partindo do pressuposto de Bakhtin (2013) acerca dos contextos em que a estrutura justaposta ocorre com maior frequência, ou seja, em gêneros mais

coloquiais e, por vezes, relacionados à fala, propomos duas atividades que visam o trabalho com gêneros textuais no Ensino Médio e Ensino Superior.

Entretanto, antes de apresentarmos tais propostas de atividades, é 
importante ressaltar que documentos que regem o ensino brasileiro, como o (PCN) e a (BNCC) Base Nacional Comum Curricular (BRASIL, 2010, 2016), apontam a necessidade de relacionar fala e escrita, levando em conta as especificidades de cada modalidade no que se refere às características linguísticas e como essas se articulam em diferentes gêneros textuais. Levando em conta a relação fala/escrita, propomos uma atividade de retextualização para o Ensino Médio.

Segundo Marcuschi (2010, p. 46), o processo de retextualização "envolve operações complexas que interferem tanto no código como no sentido e evidenciam uma série de aspectos nem sempre bem compreendidos da relação oralidade-escrita", por isso, não consideramos, nesse artigo, a retextualização como uma tarefa simples de aprendizagem, ao contrário, essa atividade é altamente complexa e linguisticamente enriquecedora para o aluno.

No que se refere ao ensino do período composto e, em especial, das cláusulas justapostas, acreditamos que o processo de retextualização auxiliará na promoção do pensamento crítico acerca da necessidade de coordenar ou subordinar ideias a depender da tipologia textual e do gênero textual estudado. Os gêneros textuais argumentativos, por exemplo, costumam ter uma frequência maior de cláusulas encaixadas e hipotáticas, enquanto os gêneros textuais descritivos e narrativos costumam apresentar um maior uso de cláusulas paratáticas e justapostas. Por isso, consideramos importante que os alunos sejam orientados a refletir sobre a correlação das estratégias linguísticas consoante as finalidades discursivas envolvidas. Sendo assim, passemos à proposta de atividade para o Ensino Médio.

Atividade 1: Dos relatos às narrativas...

Em um primeiro momento, o professor solicitará aos alunos que entrevistem os seus próprios familiares para saber/conhecer mais sobre sua história, sua ancestralidade (se possível, gravando os relatos dos familiares entrevistados). 
Em outro momento, em sala, os alunos deverão criar uma narrativa, baseando-se na história que ouviram de sua família, podendo inserir um ou dois personagens.

Após a escrita do texto, o professor, pedirá que alguns alunos, que se sentirem à vontade, leiam suas histórias.

Em seguida, o professor fará uma plenária, discutindo as descobertas feitas pelos alunos acerca das curiosidades das histórias familiares, do processo de entrevista e do processo de escrita do texto narrado pelo familiar escolhido.

Sobre esse último tópico, o professor orientará uma reflexão sobre as estratégias discursivas empregadas, dentre elas a articulação das orações.

Já no Ensino Superior, faz-se necessário pensar sobre as estratégias discursivas, principalmente no que se refere à articulação dos períodos compostos em diferentes gêneros textuais. Assim, partindo da representação do contínuo dos gêneros textuais na fala e na escrita proposto por Marcuschi (2010), apresentado a seguir, propomos a atividade para o Ensino Superior.

Figura 4 - Representação do contínuo dos gêneros textuais na fala e na escrita

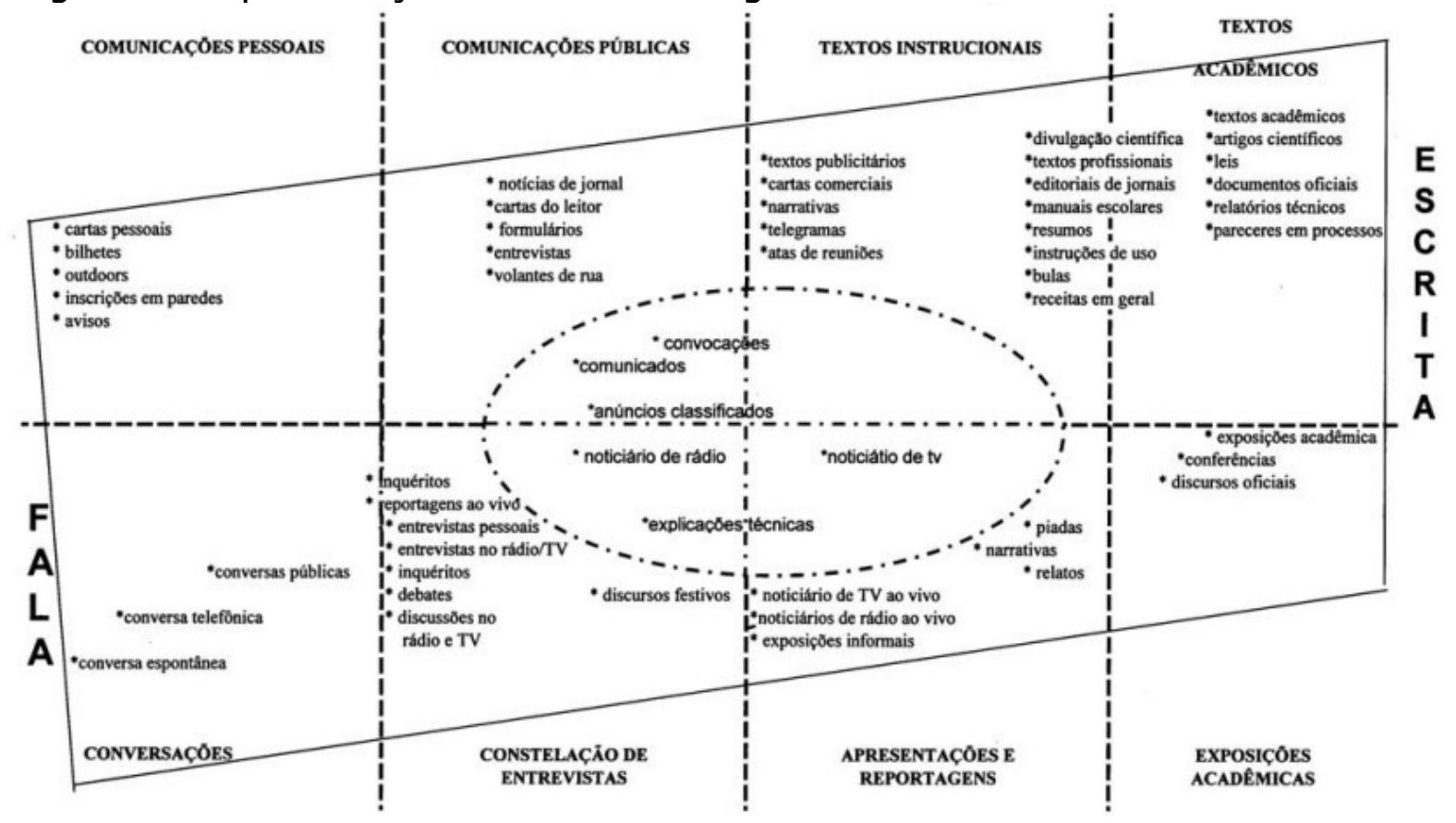

Fonte: Marcuschi (2010, p. 41). 
Atividade 2: A análise da frequência dos processos sintáticos em gêneros textuais diversos.

Em primeiro lugar, o professor solicitará que os alunos pesquisem e selecionem dois gêneros textuais orais e dois gêneros textuais escritos em textos e suportes a sua escolha.

Em seguida, os alunos terão que buscar dez textos de cada gênero selecionado e analisar a frequência de ocorrência de cada processo sintático, a saber, encaixamento (subordinação), hipotaxe, parataxe e justaposição.

Por fim, o aluno deverá criar hipóteses sobre as causas que levam a maior ou menor ocorrência de cada processo em cada gênero textual coletado, relacionando essas escolhas linguísticas às estratégias discursivas empregadas.

Ressaltamos que as duas atividades propostas visam a possibilitar a reflexão do discente acerca do seu processo de escrita, bem como a observação das estratégias discursivas empregadas em cada gênero textual. Ademais, acreditamos que as atividades não podem ser desvinculadas dos estágios de aprendizagem dos alunos, por isso, pensamos em propostas significativas e que dialogassem com os propósitos da fase escolar-universitária. Em outras palavras, no Ensino Médio, espera-se desenvolver o senso crítico do aluno, tornando-o um cidadão mais consciente de suas escolhas linguísticas, adequando-as aos diversos contextos linguísticos. Já no Ensino Superior, espera-se, além de aprimorar a visão crítica/reflexiva sobre os usos linguísticos desprovida de preconceito, desenvolver nos discentes o gosto pela investigação linguística e, portanto, visando a formação de futuros pesquisadores.

\section{Considerações Finais}

Com base na leitura das dissertações de mestrado de Gonçalves (2017) e Dias (2009) e dos estudos propostos por Bakhtin (2013), Eckert (2008) e Freitag et al. (2016), elaborou-se um teste linguístico que possibilitou investigar como alunos de Ensino Médio e Ensino Superior bem como professores de 
Língua Portuguesa e outras áreas relacionadas à área de humanas avaliavam e interpretavam a justaposição, aqui considerada processo sintático frequentemente utilizado em mídias impressas.

Apesar do teste ter sido feito de modo indireto, isto é, sem questionar objetiva e diretamente os indivíduos sobre a estrutura gramatical analisada, chegou-se a um resultado significativo sobre a percepção do fenômeno, principalmente em relação à expressividade do período composto por justaposição por alunos do Ensino Médio.

Sendo assim, esse estudo reforça também a necessidade de a escola ensinar a estilística do discurso, problematizando os usos linguísticos não prescritos pela gramática normativa em diversos gêneros textuais que estão presentes na vida cotidiana do discente, para que, como proposto por Bakhtin (2013), o aluno possa tornar sua linguagem não mais correta do ponto de vista formal, mas sim torná-la sua, sem privação de personalidade e expressividade. Assim, visando a tornar o aluno sujeito de sua escrita, propomos duas atividades de trabalho com gêneros textuais para o Ensino Médio e o Ensino Superior. Esperamos que estas propostas sirvam de estímulo à novas práticas pedagógicas, cujo principal foco de atenção seja a língua em uso.

\section{Referências}

BAKHTIN, Mikhail. Questões de estilística no ensino da língua. São Paulo: Editora 34, 2013.

BRASIL. Ministério da Educação. Base nacional comum curricular. Brasília, DF: MEC, 2016.

BRASIL. Ministério da Educação. Parâmetros curriculares nacionais. linguagens, códigos e suas tecnologias. Brasília, DF: MEC, 2000.

BRASIL. Secretaria de Educação Fundamental. Parâmetros curriculares nacionais. terceiro e quarto ciclos: Língua portuguesa. Brasília: MEC/SEF, 1998.

DECAT, Maria Beatriz Nascimento. Por uma abordagem da (in)dependência de cláusulas à luz da noção de "unidade informacional". Scripta: Linguística e Filologia, Belo Horizonte, MG, v. 2, n. 4, p. 23-38, 2. sem. 1999. 
DIAS, Maria de Lourdes Vaz Sppezapria. $A$ articulação hipotática em construções proverbiais justapostas. 2009. Dissertação (Mestrado em Língua Portuguesa) - Faculdade de Letras, Universidade Federal do Rio de Janeiro, Rio de Janeiro, RJ, 2009.

ECKERT, Penelope. Variation and the indexical field. Journal of Sociolinguistics, Toronto, v. 12, n. 4, p. $453-476,2008$.

FASOLD, Ralph. Language attitudes in the sociolinguistics of language. Oxford: Blackwell, 1984.

FREITAG, Raquel Meister Ko; SANTANA, Cristiane Conceição de; ANDRADE, Thais Regina Conceição de; SOUSA, Valéria Santos. Avaliação e variação linguística: estereótipos, marcadores e indicadores em uma comunidade escolar. In: FREITAG, Raquel Meister Ko; SEVERO, Cristine Gorski; GÖRSKI, Edair Maria (org.). Sociolinguística e política linguística: olhares contemporâneos. São Paulo: Editora Edgard Blücher, 2016. p. 141-160.

GONÇALVES, Adriana Cristina Lopes. Não é o objeto, é a perspectiva: justaposição como procedimento sintático. Uma análise sintática, pragmática e prosódica. 2017. Dissertação (Mestrado em Língua Portuguesa) - Faculdade de Letras, Universidade Federal do Rio de Janeiro, Rio de Janeiro, RJ, 2017.

LIMA-HERNANDES, Maria Célia. Expressão de tempo na conexão de orações justapostas. Domínios de Lingu@gem: Revista Eletrônica de Lingüística, Uberlândia, MG, ano 2, n. 1, p. 1-10, 1. sem. 2008.

MARCUSCHI, Luiz Antônio. Da fala para a escrita: atividades de retextualização. 10. ed. São Paulo: Cortez, 2010.

NEY, José Luiz. Guia de análise sintática. Rio de Janeiro: [s. n.], 1955.

OITICICA, José. Manual da análise léxica e sintática. 6. ed. Rio de Janeiro: Francisco Alves, 1942.

RAPOSO, Eduardo Buzaglo Paiva; NASCIMENTO, Maria Fernanda Bacelar do; MOTA, Maria Antónia Coelho da; SEGURA, Luísa; MENDES, Amália (org.). Gramática do português. Lisboa: Fundação Calouste Gulbenkian, 2013. 2 v.

RODRIGUES, Violeta Virginia (org.) Articulação de orações. pesquisa e ensino. Rio de Janeiro: UFRJ, 2010.

RODRIGUES, Violeta Virginia; GONÇALVES, Adriana Cristina Lopes. Comprou, levou? Justaposição: procedimento sintático comum em propagandas. Revista Digital do Programa de Pós-Graduação em Letras da PUC-RS, Porto Alegre, RS, v. 8, n. 2, p. 409-421, jul. /dez. 2015. DOI: http://dx.doi.org/10.15448/19844301.2015.2.20348. 